\title{
The Distance between the Pectoralis Major Tendon Insertion and the Top of the Humeral Head is a Reliable Landmark: An Anatomic Study
}

\author{
Dipit Sahu $^{1}$ Jairam D. Jagiasi ${ }^{1} \quad$ Anisha S. Valavi ${ }^{1} \quad$ Tushar Ubale $^{1}$ \\ ${ }^{1}$ Department of Orthopaedics, Dr. RN Cooper Hospital and HBT \\ Medical College, Mumbai, Maharashtra, India \\ Address for correspondence Jairam D. Jagiasi, MS, Department of \\ Orthopaedics, Dr. RN Cooper Hospital and HBT Medical College, Juhu, \\ Ville Parle, Mumbai, Maharashtra, India \\ Joints 2019;7:37-40. \\ (e-mail: orthopaedicscooper@gmail.com).
}

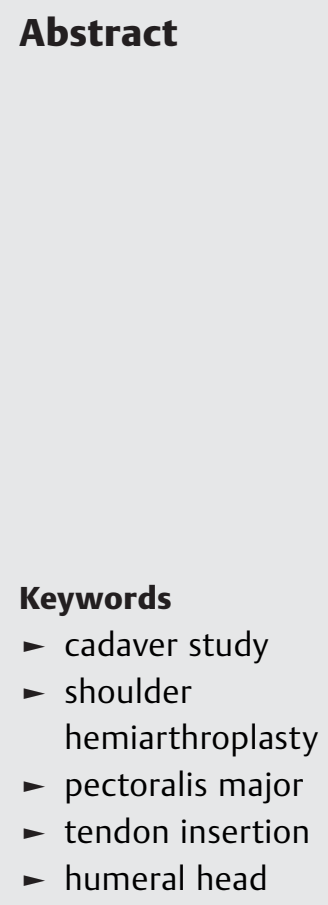

Purpose This study aimed to analyze the distance between the superior edge of the pectoralis major and the top of the humeral head and evaluate whether this distance is a consistent measurement.

Methods Twenty-two shoulders in eleven cadavers were dissected and the attachment of the pectoralis major tendon was preserved. Two distances were recorded with the help of digital vernier caliper: the distance between the upper edge of pectoralis major and tangent to the top of humeral head (PM-T) and the distance between the superomedial tip of greater tuberosity (GT) and the upper edge of the pectoralis major tendon (PM-G; \pm standard error of the means).

Results The mean PM-T distance was $53.8 \mathrm{~mm}( \pm 0.8 \mathrm{~mm})$ and the mean PM-G distance was $46.8 \mathrm{~mm}( \pm 0.9 \mathrm{~mm})$. The distance between the top of humeral head and tip of the GT was $7 \mathrm{~mm}$. The PM-T distance was a significant outlier in three shoulders as it inserted high on the humerus.

Conclusion We can conclude that the PM-T and PM-G distances were a consistent measurement.

Clinical Relevance The distance between the pectoralis major tendon and top of the humeral head was measured in this study as a reliable method that can be used intraoperatively to decide the height of the humerus prosthesis in comminuted fractures of the proximal humerus.

\section{Introduction}

Proximal humerus fractures in the elderly population can be managed by conservative methods in $80 \%$ of the cases. Internal fixation by plates is the treatment of choice in the severely displaced fractures. ${ }^{1,2}$ Internal fixation generally yields good outcomes in majority of the cases. ${ }^{1}$ However, the severely comminuted and dislocated fractures in the elderly population show poor outcomes after internal fixation. ${ }^{3}$ Osteoporosis presents another challenge for the treating physician because of the high cut out rate of screws and varus collapse of humeral head. ${ }^{3}$ These fractures may sometimes be better treated by shoulder hemiarthroplasty. ${ }^{4} \mathrm{~A}$ big challenge in shoulder hemi- arthroplasty is deciding the correct height of the humeral head prosthesis in the native bone. ${ }^{5}$ Since the greater tuberosity and lesser tuberosity are fractured in many of these fractures, the bony landmarks are not reliable to judge the height of the prosthesis. An incorrect length of the humerus may result in poor functional outcomes..$^{5-8}$ Several methods have been proposed to decide the height of the prosthesis in fractures of proximal humerus. ${ }^{9,10}$ Murachovsky et al had suggested a distance of $5.6 \mathrm{~cm}$ from the superior edge of pectoralis major tendon as a landmark to decide upon the height of the humeral head prosthesis. ${ }^{11}$ Many surgeons use this landmark intraoperatively to decide on the adequate height of the humeral prosthesis. ${ }^{12}$ Our purpose was to study the superior insertion received

July 8,2018

accepted after revision

November 4, 2019

published online

December 13, 2019
DOI https://doi.org/

10.1055/s-0039-3401818. ISSN 2282-4324.
Copyright (c) 2019 Georg Thieme Verlag License terms

KG Stuttgart · New York 
of the pectoralis major tendon and analyze whether this can be used as a consistent landmark to judge the height of the humeral head which can be later used to decide the height of the humeral head prosthesis.

\section{Methods}

Twenty-two shoulders in eleven cadavers were dissected free of soft tissues by approaching through the deltopectoral interval. None of the cadavers had any shoulder pathology. The pectoralis major insertion was preserved. The top of the head of humerus was dissected free of all soft tissues and rotator cuff attachment. The distance between the upper edge of pectoralis major and tangent to the top of humeral head (PM-T distance) was recorded with the help of a vernier caliper ( $>$ Fig. 1). The distance between the superomedial tip of greater tuberosity (GT) and the upper edge of the pectoralis major tendon (PM-G distance) was also measured. The difference between the two measurements was calculated to know the distance between the top of the humeral head and the tip of the GT. Two independent observers measured the distance and analyzed the mean data.

\section{Data Analysis}

Mean \pm standard error of the mean (SEM; 95\% confidence interval $[\mathrm{CI}]$ ) was calculated for the PM-T and PM-G distances.

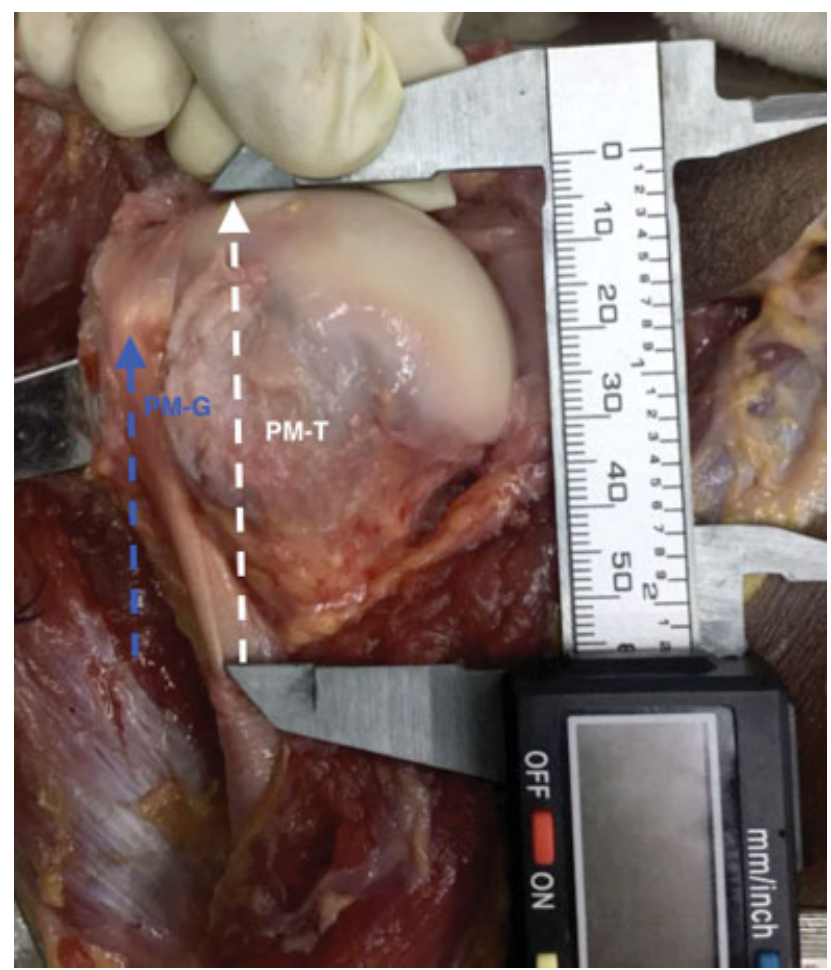

Fig. 1 PM-T distance: distance from the superior edge of pectoralis major to the tangent to the top of humeral head. PM-G distance: distance from the superior edge of pectoralis major to the superomedial tip of the GT. GT, greater tuberosity; PM-G, distance between the upper edge of pectoralis major and tangent to the top of humeral head; PM-T, distance between the superomedial tip of greater tuberosity and the upper edge of the pectoralis major tendon PM-T.
Interobserver reliability was evaluated by intraclass coefficient of correlation (ICC) with $95 \% \mathrm{CI}$.

Median, interquartile range (IQ: 75-25), and inner and outer fences calculations were done for the PM-T distance. Data points lying outside the outer fences were classified as significant outliers.

\section{Results}

Both shoulders in one cadaver and one shoulder in another cadaver had pectoralis major tendon insertion confluent with the biceps tendon sheath, which could be traced till high up the humeral head (-Fig. 2). In these shoulders, the tendon insertion near the humerus shaft was curved and not in a linear manner as was found in the other nine cadavers. The average PMT distance in these shoulders was $20 \mathrm{~mm}$.

In the rest of the nine cadavers, the mean distance from the upper border of pectoralis major insertion to the tangent to the humeral head (PM-T) was $53.8 \mathrm{~mm} \pm 0.8 \mathrm{~mm}$ $(52-55.5 \mathrm{~mm})$. The median PM-T was $53 \mathrm{~mm}$ and IQ (25-75) was 3.7 (51-54.7). The mean PM-G distance was $46.8 \mathrm{~mm} \pm 0.9 \mathrm{~mm}$ (44.9-48.8). The distance between the tip of the GT and top of the humeral head was $7 \pm 0.4 \mathrm{~mm}$ (-Table 1).

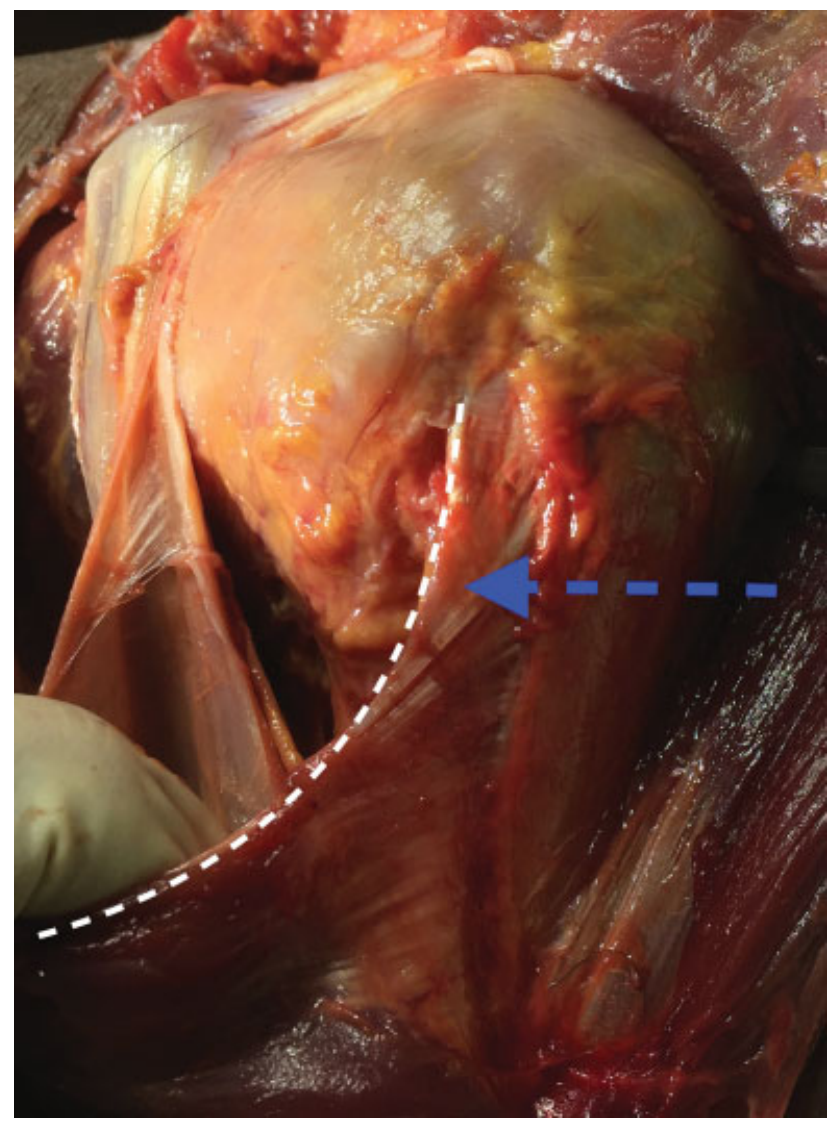

Fig. 2 Confluence of pectoralis major tendon insertion with the biceps tendon sheath-anatomical variance. White dotted line indicates the superior border of the pectoralis major tendon. Blue dotted arrow points towards the high insertion and the confluence of the pectoralis major tendon with the biceps tendon sheath. 
Table 1 PM-T and PM-G distances in nine cadavers

\begin{tabular}{|l|l|l|l|l|}
\hline \multirow{2}{*}{ Specimen } & \multicolumn{2}{l|}{ PM-T distance } & \multicolumn{2}{l|}{ PM-G distance } \\
& (mm) & \\
\cline { 2 - 5 } & Right & Left & Right & Left \\
\hline 1 & 52 & 53 & 47 & 45 \\
\hline 2 & 53.4 & 54 & 45.2 & 45.8 \\
\hline 3 & 51 & 52 & 43 & 43 \\
\hline 4 & 54.7 & 54.8 & 50.6 & 50 \\
\hline 5 & 51 & 51 & 43 & 42 \\
\hline 6 & 53 & 53 & 45 & 44 \\
\hline 7 & 57 & 56 & 52 & 50 \\
\hline 8 & 48 & 51 & 44 & 45 \\
\hline 9 & 62 & 61 & 53 & 55 \\
\hline
\end{tabular}

Abbreviations: PM-G, distance between the upper edge of pectoralis major and tangent to the top of humeral head; PM-T, distance between the superomedial tip of greater tuberosity and the upper edge of the pectoralis major tendon PM-T.

The ICC between the two observers was excellent $(0.94$; 95\% CI: 0.98-0.77). The PM-T distances (average, $20 \mathrm{~mm}$ ) in shoulders with high insertion of the pectoralis major tendon were classified as significant outliers as they lay outside the outer fence.

\section{Discussion}

In shoulder hemiarthroplasty, restoration of an accurate humeral head height with an anatomic relation between the GT and top of head should ensure proper shoulder biomechanics and good functional results. In a three- or four-part proximal humerus fracture, the anatomical landmarks of biceps groove and medial calcar ${ }^{13}$ may be fractured and cannot be accurately used as an intraoperative landmark. In our study, we found that, the PM-T distance was a constant measurement of $53.8 \mathrm{~mm}$ with a SEM of $0.8 \mathrm{~mm}$. In fractures of proximal humerus, the pectoralis major tendon is intact, thus the PM-T distance can be used as a landmark to decide the height of humeral head prosthesis. There are other methods which can be used for deciding the height of the prosthesis. Comparing the length of the fractured and normal limbs preoperatively and deciding the height of the prosthesis based on a medial part of remaining bone is one such method. However, the radiographs need to be true sized to calculate the exact length of bone. ${ }^{14}$ Some surgeons have developed jigs to judge the height, but these may be cumbersome to use. ${ }^{14,15}$

We also found that the PM-G distance was $46.8 \mathrm{~mm}$ and the distance between the top of the humeral head and the tip of the GT was $7 \mathrm{~mm}$. These distances should be respected and restored intraoperatively for an adequate rotator cuff tension. The relation between the humeral head and the GT can also be used intraoperatively for ensuring the accurate seating of the prosthesis. We can first reduce the GT as per the PM-G distance; check its position intraoperatively by fluoroscopy and then decide the height of the prosthesis. However, when the GT fracture is comminuted, this method cannot be reliably used. Restoration of the humeral head height and its relation with the greater tuberosity is important since Boileau et al have shown that even $1 \mathrm{~cm}$ of decrease in height may lower the lever arm and result in poor outcome. ${ }^{5}$ Conversely an increase in humeral head height may affect rotator cuff function and greater tuberosity healing. ${ }^{5,16}$

We found that pectoralis major inserted abnormally high in three shoulders and the average PM-T distance in these shoulders was an outlier compared with the rest of our cadavers. If this variation in anatomy is missed during the deltopectoral approach, the height of the prosthesis can be misjudged. It is our practice to judge and establish the normal insertion of the pectoralis major tendon during the initial deltopectoral exposure. Axillary nerve crosses under the deltoid within one centimeter distal to the superior insertion of the pectoralis major tendon. ${ }^{17}$ However, an appreciation of this variation will also avoid any error in the location of the axillary nerve.

The western literature suggests that the PM-T distance is 56 to $59 \mathrm{~mm} .{ }^{11,12,18}$ Murachovsky et al had first defined this distance as $56 \mathrm{~mm}$ which was independent of the height of the person. ${ }^{11}$ Torrens et al also defined this distance as $56 \mathrm{~mm}$ with a variation of $1 \mathrm{~cm} .{ }^{12}$ However, Figueiredo et al showed this distance to be $59 \mathrm{~mm} .{ }^{18}$ These differences in findings as compared with our study can be explained by the difference in the Asian and Indian bony morphology from the western counterparts. ${ }^{19-22}$ However, a study on Indian population was needed to define this distance, so that it can be used intraoperatively in the Indian population. Few other authors have also commented on variability in the PM-T distance. Hasan et al said that this distance may vary with the length of the humerus and Ponce et al mentioned that height of the individual might also affect this distance. ${ }^{23,24}$ We did not study its relation with the height of the individual, so we cannot comment on this aspect.

Similar to our finding, the relation between the top of the humeral head and the tip of the GT has been found to vary between 5 and $10 \mathrm{~mm}$, and an accurate restoration of this distance has been recommended. ${ }^{25,26}$ In another anatomic study, this distance was found to vary between 3 and $18 \mathrm{~mm} .^{27}$

\section{Limitations}

The limitations of this paper mainly include the low number of shoulders. We also did not study the relation between the height of the individual and the distance between pectoralis major tendon and tangent to the top of the humeral head.

\section{Conclusion}

We can conclude that the PM-T and the PM-G distance was a consistent measurement of 53.8 and $46.8 \mathrm{~mm}$. The distance between the tip of the GT and the top of the humeral head was $7 \mathrm{~mm}$.

\section{Ethical Approval}

This article does not contain any studies with human participants or animals performed by any of the authors. 
Funding

None.

\section{Conflict of Interest \\ None declared.}

\section{References}

1 Südkamp N, Bayer J, Hepp P, et al. Open reduction and internal fixation of proximal humeral fractures with use of the locking proximal humerus plate. Results of a prospective, multicenter, observational study. J Bone Joint Surg Am 2009;91(06):1320-1328

2 Fankhauser F, Boldin C, Schippinger G, Haunschmid C, Szyszkowitz R. A new locking plate for unstable fractures of the proximal humerus. Clin Orthop Relat Res 2005;(430):176-181

3 Jost B, Spross C, Grehn H, Gerber C. Locking plate fixation of fractures of the proximal humerus: analysis of complications, revision strategies and outcome. J Shoulder Elbow Surg 2013;22 (04):542-549

4 Zyto K, Wallace WA, Frostick SP, Preston BJ. Outcome after hemiarthroplasty for three- and four-part fractures of the proximal humerus. J Shoulder Elbow Surg 1998;7(02):85-89

5 Boileau P, Krishnan SG, Tinsi L, Walch G, Coste JS, Molé D. Tuberosity malposition and migration: reasons for poor outcomes after hemiarthroplasty for displaced fractures of the proximal humerus. J Shoulder Elbow Surg 2002;11(05):401-412

6 Becker R, Pap G, Machner A, Neumann WH. Strength and motion after hemiarthroplasty in displaced four-fragment fracture of the proximal humerus: 27 patients followed for 1-6 years. Acta Orthop Scand 2002;73(01):44-49

7 Dimakopoulos P, Potamitis N, Lambiris E. Hemiarthroplasty in the treatment of comminuted intraarticular fractures of the proximal humerus. Clin Orthop Relat Res 1997;(341):7-11

8 Goldman RT, Koval KJ, Cuomo F, Gallagher MA, Zuckerman JD. Functional outcome after humeral head replacement for acute three- and four-part proximal humeral fractures. J Shoulder Elbow Surg 1995;4(02):81-86

9 Reuther F, Müller S, Wahl D. Management of humeral head fractures with a trauma shoulder prosthesis: correlation between joint function and healing of the tuberosities. Acta Orthop Belg 2007;73(02):179-187

10 Sirveaux F, Roche O, Molé D. Shoulder arthroplasty for acute proximal humerus fracture. Orthop Traumatol Surg Res 2010;96 (06):683-694

11 Murachovsky J, Ikemoto RY, Nascimento LGP, Bueno RS, Strose E, Almeida LH. The distance between the pectoral major tendon insertion and the top of the humeral head as a landmark for proper placement of hemiarthroplasty in fractures of the proximal humerus. Tech Shoulder Elbow Surg 2008;9(02):66-69

12 Torrens C, Corrales M, Melendo E, Solano A, Rodríguez-Baeza A, Cáceres $\mathrm{E}$. The pectoralis major tendon as a reference for restoring humeral length and retroversion with hemiarthroplasty for fracture. J Shoulder Elbow Surg 2008;17(06):947-950

13 Hromádka R, Kuběna AA, Smíd M, Popelka S. Medial calcar of proximal humeral fracture as landmark in restoration of humeral length in case of hemiarthroplasty. Surg Radiol Anat 2014;36(05): 473-479

14 Boileau P, Winter M, Cikes A, et al. Can surgeons predict what makes a good hemiarthroplasty for fracture? J Shoulder Elbow Surg 2013;22(11):1495-1506

15 Frankle MA, Mighell MA. Techniques and principles of tuberosity fixation for proximal humeral fractures treated with hemiarthroplasty. J Shoulder Elbow Surg 2004;13(02):239-247

16 Boileau P, Walch G. The three-dimensional geometry of the proximal humerus. Implications for surgical technique and prosthetic design. J Bone Joint Surg Br 1997;79(05):857-865

17 Shiu B, Jazini E, Robertson A, Henn RF, Hasan SA. Anatomical Relationship of the Axillary Nerve to the Pectoralis Major Tendon Insertion. Orthopedics 2017;40(03):e460-e464

18 de Figueiredo EA, Terra BB, Cohen C, et al. The pectoralis major footprint: An anatomical study. Rev Bras Ortop 2013;48(06): 519-523

19 Kim TK, Phillips M, Bhandari M, Watson J, Malhotra R. What differences in morphologic features of the knee exist among patients of various races? A systematic review. Clin Orthop Relat Res 2017;475(01):170-182

20 Zhang L, Yuan B, Wang C, Liu Z. Comparison of anatomical shoulder prostheses and the proximal humeri of Chinese people. Proc Inst Mech Eng H 2007;221(08):921-927

21 Aroonjarattham P, Jiamwatthanachai P, Mahaisavariya B, Kiatiwat T, Aroonjaratthammd K, Sitthiseripratip K. Three-dimensional morphometric study of the Thai proximal humerus: cadaveric study. J Med Assoc Thai 2009;92(09):1191-1197

22 Zhou J, Zhang L, Shen L, Zhu M, Zheng F. Analyzing on the location of the bicipital groove for alignment in shoulder arthroplasty of Chinese. J Orthop Sci 2017;22(03):425-429

23 Hasan SA, Rauls RB, Cordell CL, Heinzelmann AD, Siegel ER. Pectoralis major insertional ratio in proximal humerus fractures: a method to reconstruct humeral head height in arthroplasty. Orthopedics 2009;32(10):. Doi: 10.3928/01477447-20090818-13

24 Ponce BA, Thompson KJ, Rosenzweig SD, et al. Re-evaluation of pectoralis major height as an anatomic reference for humeral height in fracture hemiarthroplasty. J Shoulder Elbow Surg 2013; 22(11):1567-1572

25 Demirhan M, Kilicoglu O, Altinel L, Eralp L, Akalin Y. Prognostic factors in prosthetic replacement for acute proximal humerus fractures. J Orthop Trauma 2003;17(03):181-188

26 Mighell MA, Kolm GP, Collinge CA, Frankle MA. Outcomes of hemiarthroplasty for fractures of the proximal humerus. J Shoulder Elbow Surg 2003;12(06):569-577

27 Iannotti JP, Gabriel JP, Schneck SL, Evans BG, Misra S. The normal glenohumeral relationships. An anatomical study of one hundred and forty shoulders. J Bone Joint Surg Am 1992;74(04):491-500 